\title{
BONFIM: FEIÇÕES DE UMA CIDADE NO PLURAL... OU O LUGAR DA DESORDEM ${ }^{1}$
}

\author{
Ana Luiza Carvalho da Rocha ${ }^{2}$
}

Para se compreender o lugar da desordem como central da feição plural da ambiência urbana das cidades brasileiras proponho aqui que se possa avançar para alem da perspectiva que pensa sua atmosfera de socialidade em termos de um corpo de imagens polêmicos: a casa e a rua.

Gostaria de evitar as armadilhas de tais polêmicas entre essa duas imagens diferenciadas para pensar, na análise do bairro Bonfim, em Porto Alegre, a idéia que o teatro da vida urbana local se compõe de uma "casa de ruas" que os habitantes habitam em seus percursos e itinerários quotidianos. Mesmo que este bairro possa ser considerado um lar menos tranqüilo que nossa casa natal, parece-me duvidoso que tal bairro não possa expressar a adesão de uma comunidade de destino a poética espacial de seus territórios.

Segundo Da Matta ${ }^{3}$, sociedade brasileira, desde suas origens remotas, vive um dilema eterno entre tradição e modernidade. No interior de tal dilema ocorrem tensões entre os espaços sociais da casa e da rua., onde o autor assinala a oposição entre as categorias sociológicas de Pessoa e de Indivíduo no Brasil. Em nosso país, diria Da Matta, a rua é um lugar de vagabundagem e do homem, encerrando o mundo do trabalho, das relações impessoais, da competição e do profano. Por oposição, o espaço da casa revelaria o mundo doméstico, da mulher, do sagrado, da família e do repouso.

\footnotetext{
${ }^{1}$ Palestra proferida na Mesa Redonda Cidades, bairros e territórios: enraizamentos da memória, Seminário A Cidade plural, cultura e política no espaço urbano. Secretaria da Cultura/ Museu Antropológico do Rio Grande do Sul/ UFRGS, ago.1995.

${ }^{2}$ Este artigo é resultado de uma pesquisa financiada pelo CNPq no período de 1987/88. Agradeço aqui a Flavia Rieth com quem dividi a pesquisa da campo no Bairro Bonfim e Vila Ypu, as idéias e os argumentos aqui apresentados. Agradeço igualmente as ricas sugestões de Carmen Silvia Rial, colega de meu período de doutoramento na França, quando retomei a escritura deste artigo.

${ }^{3}$ Roberto Da Matta, a partir de um novo paradigma, amplia as reflexõees sobre a sociedade brasileira, honrando uma tradição do pensamento sociológico do Brasil abandonada, nos últimos anos, pelas ciências sociais (como por exemplo, G. Freire, Nina Rodrigues, Sérgio Buarque de Hollanda). Suas obras como Carnaval, malando e heróis, para uma sociologia do dilema brasileiro (1983) e A Casa e a Rua, espaço, cidadania, mulher e morte no Brasil (1985), O que faz do brasil, Brasil (1986).
} 
Certamente tais observações pertinentes deste autor encontram-se fortemente marcadas nas obras de Gilberto Freire, ${ }^{4}$ onde esse autor aponta , como uma das razões para este fenômeno, o traço sincrético que caracteriza a fisionomia da cultura brasileira capaz de incorporar uma mistura singular das mais diversas formações culturais de significação.

Gostaria de re-situar este tema do "dilema da sociedade brasileira" no corpo de uma reflexão acerca da civilização urbana local, pois acredito ser ainda uma rica forma de análise da vida quotidiana dos moradores do Bonfim.

Reconhecendo-se que a cultura brasileira vive, desde a formação de seu corpo coletivo, a ambivalência entre a adesão a uma tradição patriarcal e hierárquica, cujo espaço social de inscrição é a casa, e a adoção dos postulados do individualismo moderno, cuja expressão simbólica revela-se no espaço social da rua, o estudo da vida quotidiana dos moradores de um bairro como o Bonfim pode nos revelar inúmeras facetas não de uma ambivalência Casa/Rua, mas da harmonia conflitual entre tais inscrições espaciais do corpo coletivo das cidades brasileiras.

Com efeito, uma pesquisa de 6 meses neste bairro, 1982/87, abordando o tema da infância e da família, nos revelou que na vida quotidiana de seus moradores é a presença de uma harmonia tensional de tais espaços e seus significados, sendo isto um fenômeno que expressa a "aura estética" do Bonfim desde a perspectiva da sua memória coletiva no teatro da vida urbana local.

O gosto coletivo pela aglomeração faz do Bonfim um bairro tradicional da cidade de Porto Alegre, evocando em sua socialidade polimórfica que engendra uma mistura tensional de espaços morais e éticos tão distintos como aqueles que contemplam a Casa e Rua no modelo interpretativo de Da Matta.

Não por acaso, o Bonfim é sempre, e eternamente, atingido pela preocupação com os efeitos morais malignos do caos e da desordem do espaço urbano. Assolado processos de desfiguração de seu patrimônio edificado, o seu território não é apenas lugar de enraizamento da aventura e da boêmia, mas do policial, território assolado por ondas de ações discursivas que tentam associa-lo a violência, a delinquiência e a criminalidade urbana local. ${ }^{5}$

Nada mais fácil de enfocar, então, a vida no Bonfim a partir da máxima "em casa o brasileiro é um rei, na rua, um vagabundo". Imagem da vagabundagem noturna, (e apesar da

\footnotetext{
${ }^{4}$ Ver as obras de G. Freire, Casa Grande e Senzala, estudo sobre a formação da sociedade brasileira, e Sobrados e Mocambos.

${ }^{5}$ A propósito de outros exemplos em cidades brasileiras ver A. Zaluar A máquina e a Revolta, 1985 e T. Caldeira A política dos Outros, 1984.
} 
atmosfera comercial e familiar) o Bonfim expressa parte da lógica do prazer e da errância de grupos urbanos onde a rua transfigurando-se em casa ocupa um papel central na atmosfera hedonista das cidades brasileiras.

Não por acaso o culto ao hedonismo do morro, das favelas e escolas de samba que fizeram do Rio de Janeiro, no turismo internacional e nacional, a marca registrada da exuberância e luxuria das cidades tropicais produzem uma polarização de imagens associando, recentemente, a "cidade maravilhosa" à criminalidade e marginalidade urbanas; apresentando-a aos olhos como a imagem degradada da vida metropolitana e de sua população urbana local.

Para além de uma visão catastrófica das grandes cidades brasileiras e de suas zonas de socialidade coletiva "quentes" (nos termos de Lévi-Strauss), trata-se de se avançar num outro paradigma da vida social urbana do Brasil, ou seja, enfocar seus territórios a partir do quotidiano de seus moradores e das marcas afetivas que os ligam a tais espaços. ${ }^{6}$

Desta forma, poderemos compreender a forma que encontram seus habitantes de reapropriar-se do espaço da rua como se este fosse seu lar, como território abrigo e refugio. É somente em nossa adesão a potência subterrânea dos valores oníricos que ligam os moradores a tais locais que podemos restaurar a integridade da vida na cidade e ultrapassar suas imagens de deformação e monstruosidade ligado ao roubo, ao crime, ao estupro, a morte.

\section{Redescobrindo o bairro Bonfim}

Pois bem, é o momento de se explorar as idéia esboçadas em torno da poética da apropriação e recriação da ambiência urbana do bairro Bonfim através do aprofundamento da infância e da vida familiar neste território.

Convido o leitor a percorrer o território do Bonfim e a admirar, com os olhos de seus habitantes mirins, a atmosfera calorosa e plural que ele lhes reserva, apesar de seu estigma como espaço que contém uma matéria diabólica. Para se chegar a sentir tal panorama talvez seja necessário aqui um pouco das lembranças e reminiscências históricas que o Bonfim guarda no imaginário e folclore popular da cidade de Porto Alegre?

\footnotetext{
${ }^{6}$ Inspiro-me aqui no tema da "sensualizaçào da existência desenvolvido por M. Maffesoli em sua obra Aux Creux des apparences, Plon, Paris, 1990.

${ }^{7}$ Considerando que este artigo resultou de uma pesquisa comparativa da infância e família em dois bairros de Porto Alegre (Bonfim e Vila Ipu), valho-se aqui de algumas comparações esclarecedoras da paisagem urbana deste bairro popular para falar do bairro Bonfim.
} 
Mas antes, gostaria de fornecer alguns dados estatísticos reveladores do que direi a seguir a respeito do bairro Bonfim no corpo das feições da cidade no plural.

O bairro Bonfim tem uma população regularmente distribuída na faixa etária dos 0 aos 64 anos de idade, com uma concentração expressiva nas faixas dos 20 aos 39 anos (38,96\% do total), que poderíamos classificar, pelos dados do IBGE (1991) como eminentemente de adultos jovens, solteiros ( taxa de conjugalidade é de 45,49\%, com prole não extensa e de pessoas com faixa etária acima de 70 anos é de 8,50\%).

Em termos de moradia, segundo a mesma fonte, 95,73\% da população local habita em prédios de apartamentos, sendo que 57,23\% são proprietários de seus domicílios, havendo uma média de 6 cômodos por domicílio onde habitam igualmente uma média de 3 pessoas, em sua maioria os chefes de família possuem $3^{\circ}$ grau.

No interior da genealogia da estética urbana plural e confusional de Porto Alegre, o bairro Bonfim pode ser considerado como expressão local da personalidade sincrética do homem brasileiro que engendra o gosto pelo encontro coletivo, de estar-junto-com, de uma sensualização da existência que caracteriza a maior parte das manifestações culturais vida urbana desta cidade e que provavelmente acena para a composição da trajetória social de seus moradores: adultos jovens em processo de consolidação de um estilo de vida de camadas médias urbanas.

Entretanto, mesmo com sua feição estratificada de camadas médias, o bairro Bonfim abriga, como inúmeros outros locais de enraizamento de uma vida coletiva pluralista em seus diversos ciclos temporais, imagem do perigoso e do monstruoso para práticas urbanísticas preocupadas com o disciplinamento da vida urbana local. $\mathrm{O}$ bairro tem sua paisagem urbana progressivamente modificada com a construção de conjuntos comerciais em detrimento de sua fisionomia residencial.

Enquanto abrigo, nos anos 80, de tribos urbanas "alternativas" (os punks, os darks, os yuppies, os ecologistas) e refugio de poetas, boêmios, intelectuais e vagabundos de varias regiões da cidade, este bairro é visto e reconhecido na memória da cidade como um território que manteve e fez perdurar o ato de adesão afetiva de seus moradores no seio das transformações urbanas sofridas na sua paisagem urbana.

Já na época da Porto Alegre colonial, período da instalação da vida urbana local, o bairro fazia parte do antigo território dos Campos do Bonfim, região habitada por escravos que para ali fugiam longe dos maus-tratos dos seus senhores ou negros-de-ganho que ali residiam, em seus 
mocambos, por não haver mais lugar de moradia para a escravaria no novo complexo cultural habitacional do sobrado.

Neste território, e em suas cercanias, diz o folclore popular estas populações de desenraizados construíam suas habitações miseráveis e praticavam seus rituais e sua convivialidade.

A medida que a civilização urbana avançava para além da parte intra-muros (o centro da cidade), em direção ao antigo Caminho Novo (Avenidas Osvaldo Aranha e Protásio Alves) e à estrada da Aldeia dos Anjos (Av. Independência), o bairro definia seus limites e fronteiras com outras feições da cidade, altera-se sua fisionomia abrigando toda a sorte de pequenos comerciantes, com seus casarios baixos, suas carroças e seus cavalos deixados nas pastagens dos Campos da Várzea.

Sua proximidade, como passagem/meio, para outras regiões da cidade, fez com que o Bonfim adquirisse feições marcadamente de fronteira cultural e étnica da Porto Alegre imperial que começava a povoar-se, desfrutando da transfiguração da paisagem rústica dos acampamentos de tropeiros e das casas de batuque dos Campos da Várzea em Parque da Redenção.

Sofrendo os efeitos da civilização urbana, no período da cidade democrática do séc. XX, o bairro Bonfim será ocupado pelos primeiros imigrantes judeus, povoados com suas boutiques e casas comerciais e sinagogas, compartilhando os novos espaços do Parque da Redenção que surgem para abrigar a Exposição Internacional da Industria, em 1901.

Tendo absorvido a atmosfera de agitação cultural dos antigos territórios de socialidades coletivas, o velódromo e a praça de touros, o dia-a-dia no interior das ruas locais nutre-se, agora, da vida intelectual e cultural m interior do quarteirão universitário, o vai-e-vem dos colegiais do Instituto de Educação e dos alunos da Escola Militar.

Breve, nos caminhos e descaminhos da atmosfera democrática que reina em Porto Alegre, o Bonfim passa a congregar um tipo de socialidade coletiva confusional que ali imperava, numa extensão da vida boêmia do centro da cidade. Da agitação política que reinava nos cafés, bares, casas de espetáculos e cinemas da Porto Alegre dos anos 20-40, o Bonfim herda a ambiência das conspirações e manifestações estudantis secundaristas e universitárias dos anos 50 e 60 . Tal atmosfera de efervescência cultural se amplia, nos anos 70 e 80, quando o Bonfim absorve novas socialidades coletivas, se tornando território de enraizamento de tribos urbanas (homossexuais, ecologistas, punks), das lojas de produtos naturais, de templos de grupos esotéricos que dividem, junto com o bar Lola, Lancheria do Parque e Ocidente, as atenções das autoridades locais. 
Tornado mais moderno, seu casario antigo dá lugar a prédios em estilo modernista. No interior da vida do bairro, a ambiência se altera. Rasgam-se novas avenidas e ruas mais largas, amplas, ao sabor da circulação volátil de pessoas e carros em direção a outras áreas limítrofes da cidade. Surgem edificações para fins comerciais e sede de bancos (antes existentes no centro da cidade), butiques cujas fachadas em vidro refletem a imagem da ambiência urbana da rua, permitindo aos pedestres imitar o gesto de Narciso diante do lago.

O ritmo dos tempos que preside os anos 90 acrescenta a esta paisagem ornamental que atinge as partes “modernas' do bairro a invasão de camelôs e mascates com suas bancas improvisadas, repletas de toda a sorte de bugigangas a atormentar os comerciantes locais.

Tais habitués dos anos 90, nos convidam a olhar outras ruas menos nobres dos bairros e seu emaranhado de postes de eletrificação, repletas de velhas casas e antigos prédios de apartamentos cujos muros resistem bravamente a ação do tempo, adornadas por arvores maltratadas e mal podadas, cobertas de parasitas, circundados de calçadas cujo pavimento irregular desafia os pés mais incautos.

Interrogo-me aqui se por acaso não é a força da viscosidade de laços coletivos que se cruzam na atmosfera híbrida e confusional do bairro que sempre atrai o Bonfim no imaginário urbano da cidade de Porto Alegre. ${ }^{8}$

\section{Era uma vez uma rua...}

E tempo agora de convidá-los a percorrer certas ruas do bairro com os olhos de 7 crianças, meninos e meninas que tinham na ocasião da pesquisa (1989), entre 5 a 10 anos. Com tais crianças tive uma experiência singular de apropriação da ambiência urbana do bairro Bonfim, onde , na ocasião, eu morava. Torna-se necessário pontuar que em minha pesquisa eu me sentia tão próxima dessas crianças que esquecia freqüentemente minha condição de adulto. Com isto me

\footnotetext{
${ }^{8} \mathrm{Na}$ mesma ocasião realizava pesquisa na Vila Ypu, com crianças pertencentes a escola do bairro e a paisagem contrastava com o Bonfim. A Vila Ypu realizava uma paisagem de bairro operário. Ou seja, seu corpo de imagens estava associado a um espaço do repouso daquele que trabalha uma vez que seus habitantes, na maioria homens, deslocavam do bairro pela manhã para trabalhar em zonas industriais da capital. Bastante freqüente é a comparação, no interior da população de trabalhadores urbanos, entre o loteamento e a favela que circundava o morro. Tal território era considerado uma região de vagabundos, de delinqüentes e de criminosos. Minha pesquisa com famílias moradoras nos dois territórios revelou uma gama de pré-conceitos no interior de uma mesma camada social. A tensão e, algumas vezes, a violência entre eles fazendo parte de uma ausência de ambiência confusional de convivialidade. Assim, a vila Ypu passa a ser habitada por toda uma fantasmagoria do Estranho, pesar da imagem de "arcádia" que aqueles que projetaram o loteamento na área central da Vila quiseram adotar.
} 
perguntava se o que nos aproximava uns dos outros não era uma espécie de experiência plástica de adesão ao território da rua.

É. assim, que gostaria de introduzi-los no espaço do bairro Bonfim, percorrendo os lugares de aventura deste grupo de crianças, como de muitas outras moradoras do bairro na ocasião, do espaço citadino da rua. Assim, tão longe nos distanciemos das avenidas, ruas e entroncamentos mais movimentados e que se chegue as ruas secundárias deste bairro, pode-se observar a presença de grupos de crianças. Da mesma forma que estas crianças, o grupo que investiguei tinham por hábito de fazer da rua um território de divertimento e brincadeira, mesmo em desobediência aos conselhos e proibições de seus pais.

Por entre os diversos lugares que chamavam a atenção deste grupo de crianças, haviam alguns preferidos. Era em torno deles que se reuniam incessantemente. Permaneciam em volta das pequenas lojas e de suas vitrines repletas da sedução de guloseimas e de figurinhas autocolantes cujos álbuns acabavam de sair, da mais recente edição de uma revista em quadrinhos. Sem cessar eles se divertiam comprando iô-iôs e chicletes, saboreando sorvetes, balas e bombons adquiridos nos quiosques das esquinas.

Sempre, após um passeio no paraíso do consumo, esses grupo de crianças se reuniam entorno dos muros das residências esperando os amigos chegarem da escola para convidá-los para um bate-papo, um pega-ladrão, um esconde-esconde, um jogo de futebol em determinados entroncamentos menos movimentados dos bairros. O convite podia envolver a troca de figuras autocolantes, repetidas nas escadas internas e externas dos edifícios ou mesmo para contarem o que lhes havia acontecido na escola ou falar mal da síndica de um certo edifício que lhes proibia de brincar nos arredores.

Atentos a uma sociedade de consumo essas crianças, como seus pais, eram fascinados pela ambiência de territórios do consumo local: supermercado, padarias e confeitarias, lojas de brinquedos. Os objetos que consumiam funcionavam como um certo emblema de entrada num clube muito especial: o grupo da zona.

Para possuir tais objetos-emblemas, de tempo em tempo, tornava-se necessário a aventura e o desafio de se atravessar ruas e avenidas mais movimentadas do bairro, desafiando os seus limites de apropriação quotidiana do bairro. Numa apropriação poética dos "perigos" da cidade, simbolizados na agitação da ambiência da rua, do trânsito de veículos e de pessoas, dos sinais, da 
parada e saída de lotações, o bairro se revelava para estas crianças um lugar de superação dos limites e regiões morais do bairro impostas por suas famílias de origem.

Como um ritual de passagem, uma vez que estas "investidas" nas áreas "quentes" do bairro significam, para os que tinham mais idade, um afastamento da casa materna, a "travessia da rua" era sempre para os menores fonte de prazer e sedução.

Em conseqüência, freqüentemente, para o grupo orientava na rua por uma estranha forma de separar o "aqui" do "lá". O "aqui” era sempre empregado para falar dos lugares mais conhecidos do bairro, regiões já "domesticadas". o "aqui" era a imagem de um lugar no interior do qual os sonhos e brincadeiras do grupo já haviam encontrado um repouso- um lar na ca de ruas. O "aqui", um espaço de enraizamento, representava para as crianças um sentimento de "estar dentro". Lugar intimo e refúgio feliz localizado no interior do território da rua onde eles se sentiam ao abrigo do "estrangeiro". Ao contrário, o "lá" exprimia a tentação da aventura, do desconhecido e do mais remoto. Uma região qualquer que eles sentiam-se desafiados a se apropriarem segundo sua vontade e desejo de trabalhar a imaginação do lugar. O "lá" era, freqüentemente, lugar que evocava o desejo de conquista, o sentimento de ir contra uma substancia imaginaria "proibida" no corpo do décor urbano.

Mas é necessário se salientar que um tal corpo de imagens (o "aquile o "lá") se constrói neste grupo de crianças na medida em que as ruas do bairros são apropriadas enquanto espaço habitado e que elas não se prendem a um lógica moral. ${ }^{9}$ Bem ao contrário, este corpo de imagens representa diferentes tipos de vínculos emocionais deste moradores mirins com o território do Bonfim e do caráter de imensidão que a rua lhes evoca como ponto de partida para seus devaneios de intimidade.

É evidente que esta significação poética do território da rua para as crianças investigadas torna-se sempre mais rica quando se observa a forma como eles brincam na rua e tiram proveito, no seu mundo onírico da infância, de toda a matéria do décor urbano.: o tecido acidentado e caótico das ruas e calçadas repletas de turbulência, de todo o tipo de formas e imagens que cada criança

\footnotetext{
${ }^{9} \mathrm{O}$ mesmo se encontrou em nossa experiência de convivialidade infantil na Vila Ypu, só que regido por valorações de estruturas espaciais diferentes. O “ aqui " traduz o espaço da moradia, ligado ao corpo de imagens do refúgio e da proteção, Por outro lado, o "lá" é adensado com o "lá longe", território do morro, da favela e do mato, dos vagabundos e ladrões. território do estranho, do mistério, do perigo. A vegetação do mato, próxima a área do loteamento, repleta de pequenos animais, pedras e alagadiços é lugar de brincadeiras, do mundo dos super-heróis e superpoderes. Arvores, pedras, matagal transformam-se em monstros planetários e seres fantasticos apesar da insistência das famílias para "fixarem" em suas residências e reduzidos pátios.
} 
explora participando, neste terreno acidentado numa espécie de "luta cósmica" contra o ambiente urbano.

Poderia dizer que tais crianças se divertiam explorando os ritmos e modificações das condições do tempo no espaço de seu bairro. À tardinha, quando os habitantes das sombras tornavam-se mais aterradora a ambiência do lugar, com o sol se pondo por entre arvores, edifícios e carros dando-lhes contornos estranhos, era o momento de se brincar de "esconde-esconde".

Disto pode-se deduzir a forma como este grupo de crianças apropriava-se, na dinâmica do corre-corre e da gritaria, a entrada dos edifícios e das velhas casas, seus muros, suas garagens e suas escadarias, as arvores e os carros estacionados ã beira da calçada. Repentinamente, tais espaços habituais tornava fonte de emoção e prazer. ${ }^{10}$

A ambigüidade do ser visto e não ser reconhecido, de desaparecer mas também da aventura de mostra-se; o desafio de ser descoberto por um parceiro de brincadeira e, logo em seguida, de descobrir os outros. Aqui a matéria do décor urbano que compõe a rua é objeto de extroversão dos sonhos e devaneios os mais felizes destas crianças.

$\mathrm{O}$ mesmo ocorre quando se observava a forma que tais crianças exploravam o território do bairro em que moravam por ocasião de uma tempestade quando o divertimento era de afrontar a cólera do vento entre os edifícios e casas para, logo depois, brincar nos caminhos cobertos de poças de água que se formavam nas calçadas. Eu ouso confessar que em inúmeros momentos que observava tais brincadeiras, eu mesma me sentia como uma criança atraída pela atmosfera de contos de fadas e super-heróis que impregnava as ruas nas quais elas brincavam.

Uma vez desafiados a matéria do território compreendido pela rua e aderindo aos apelos de suas formas, estas crianças exploravam os diferentes revestimentos das calçadas, a disposição de suas pedras para ali jogarem "amarelinha" experienciando o desafio de concentrarem-se, durante seu deslocamento, nos limites precisos do caminho desenhado no solo pela regularidade imprecisa das suas pedras. Diversão esquisita uma vez que, neste jogo, à medida que a criança se desloca no sentido horizontal ao mesmo tempo desloca-se num percurso vertical imaginário. Neste momento,

\footnotetext{
${ }^{10} \mathrm{Na}$ Vila Ypu, em particular, na área do loteamento mais do que na favela, a adesão poética das crianças ao espaço da rua é bloqueada tanto pelo código moral de suas famílias (propensas aos valores modernos de contração de sociabilidade pública) quanto por suas estruturas espaciais homogeneizadoras. As crianças moradoras deste território permanecem grande parte do tempo em casa, fechadas, longe da grande aventura da rua. Isto faz a fuga da casa um aventura sem limites, espécie de expedição perigosa que, em sendo descoberta, é imediatamente punida.
} 
tudo se passa como se ela subisse escadas desenhadas no chão, pelas pedras irregulares que a conduziriam do inferno ao céu, e vice-versa.

Outras vezes, pela força da ambiência urbana do Bonfim, estas crianças eram, assim, atraídas pela aventura da exploração da vertigem de percorrer e se deslocar com seus patins de roda, de bicicletas e skates as regiões acidentadas de certas ruas do bairro onde o revestimento das calçadas eram regulares e em lombas.

Era a emoção de uma queda inesperada, a sensação física da aceleração corporal e da domesticação heróica do tempo na apropriação volátil dos seus espaços. Era graças a esta forma plural e diferenciada de suas edificações e paisagens que tais crianças gastavam seu tempo ao abrigo da rua, subindo nas suas velhas arvores e muros para ali sonharem seus devaneios de imensidão.

Olhando e divertindo-se com os diferentes tipos humanos do lugar que passavam lá embaixo, tão pequenos, eles encontram-se num outro bairro, não aquele de seus pais e dos adultos, mas o bairro Bonfim de seus dias de infância. Parece-me, portanto, plausível considerar que o ato de brincar e se divertir que orienta a vida quotidiana deste grupo de crianças que habitava o bairro Bonfim, em 89, é tributário de outros gestos, o dos moradores adultos locais.

Enquanto visita a esta "casa de ruas" que é o bairro, estas crianças como seus habitantes, participam de um passeio quotidiano por uma rede de percursos e caminhos repletos de lugares de encontros coletivos, de acidentes e de vazios, de movimentos de expansão em direção a vida comunitária local e de retração. Fascinados pelos elementos heterogêneos constitutivos da paisagem urbana do Bonfim, reunindo o velho e o novo, o antigo e o moderno, seus territórios heterogêneos constituem-se num apelo a extroversão e introversão do rico mundo onírico da infância.

Os acidentes de percurso, as fronteiras entre a rua e a casa, a ambiência muitas vezes degradadas das calçadas, das portas de prédios, das arvores e dos muros de construções antigas, os sinais de trânsito, a circulação de pessoas e carros fazem parte de uma aventura imaginaria que as crianças estudadas dividiam entre elas. Muitas vezes a compra de um mero chiclete numa das avenidas mais movimentadas do bairro representam uma extraordinária expedição rumo a feição moderna da cidade em que habitam, a seus verdadeiros "não-lugares". Experiência estética que, diria eu, talvez impregne o fenômeno da delinqüência existente no local: o desafio de conquistar um espaço turbulento e misterioso que é a rua, tornando-o uma verdadeira morada.

\section{Para além de imagens infernais}


Atentos a tudo o que se disse aqui sobre as formas de vida coletiva destas crianças no bairro Bonfim, pode-se sugerir aqui que, assim como eles, seus habitantes adultos, também são íntimos e solidários do caos da polifonia e polissemia da atmosfera das ruas dos Bairros, não só concebidas como lugar de passagem.

Aos meus olhos, o que me fascina no bairro Bonfim, e que apresento aqui, nestas imagens dispersas, é que se pode falar deste território e de seus habitantes a partir de suas cenas de rua. Como uma espécie de "cidade oceano", ${ }^{11}$ sua paisagem é marcada, pela manhã, pelo murmúrio das conversas nas suas esquinas e calçadas, o barulho incessante de seus habitantes, nos muros e nas portas dos edifícios,: crianças, velhos, mães de família, feirantes, o vai-e- vem de mendigos, profissionais liberais, operários.

A vida do bairro reaparece, a cada dia, com a adesão de seus habitantes a essa "morada de ruas". Como uma espécie de "esquina do mundo", a vida quotidiana dos moradores locais adere à rítmica de um tempo social, em presença dos intervalos compreendidos na polêmica das imagens, de um lado, do dia e da noite, e por outro, do trabalho (a semana) e do prazer (o fim de semana).

Gostaria de abordar aqui a rítmica do tempo social e a lógica dos símbolos que conduz os moradores do Bonfim a recriarem a ambiência da casa nas ruas do bairro.

Durante a semana, um verdadeiro corpo de sonoridades invade as janelas das residências locais, reunindo seus moradores à ambiência das ruas do bairro: a chegada e saída de carros em frente aos edifícios, entrega de mercadorias nos supermercados e lojas, os trabalhos de construção de um prédio de apartamentos, no espaço vazio de um antigo sobrado. Tudo isto, sem esquecer os odores da transpiração de operários, dos produtos vendidos nas pequenas mercearias, da comida feita na cozinha de restaurantes populares, do cafezinho, da cachaça e da cerveja nas mesas dos bares.

Este mesmo cenário se recria, tanto pela manhã como à tardinha com o deslocamento de pessoas nas portas das escolas, bares, quitandas e creches, com fofocas das empregadas domésticas em frente aos edifícios, com os aposentados e suas cadeiras nas calçadas, uns a

\footnotetext{
${ }^{11}$ A expressão cidade oceano e empregada por G. Bachelard, La poétique de l'espace, Puf, Paris, 1989. Com relação a Vila Ypu pesquisada no mesmo período, esta metáfora não pode ser empregada pois sendo um loteamento planificado a rua é um espaço deserto - um deserto de cimento. Sem comercio local, sem local de encontro coletivo, à exceção da calçada na frente das edificações. A ambiência do bairro é repleta de ruas alinhadas, sem arvores, com casas e edifícios fechados, sem lojas ou comercio, padarias ou cafés. A planificação do bairro destruiu a atmosfera de barulho e agitação que caracteriza o centro da cidade. Isola-se a turbulência da atmosfera urbana do centro do bairro para os morros e sua rede de caminhos complicados que formam a favela próxima ao loteamento onde moram os antigos moradores do bairro.
} 
conversar sobre suas lembranças de outras épocas, outros discutindo os últimos escândalos de personalidades públicas locais.

Sem dúvida, os moradores locais nutrem uma certa ambivalência em relação ao traço confusional da vida coletiva no bairro que, segundo muitos deles, acarretaria suas imagens de furto, roubo e morte no corpo das representações da violência e criminalidade urbana de POA. ${ }^{12}$ Mas a violência e arbitrariedade policial, em suas intervenções locais à noite também força seus habitantes a redefinirem a imagem do bairro como lugar perigoso.

Da mesma forma, seja à tardinha, momento em que a luz do dia que se apaga e as sombras da noite que avançam sobre o bairro, seja cedo da manhã, quando o sol desperta e a lua encontra seu repouso, a ambiência do bairro chama ao encontro coletivo, a troca indiferenciada coisas e pessoas.

No encontro desses dois momentos, o bairro acolhe um mundo intenso de trocas sociais, verdadeira "morada de ruas" pela proliferação de pequenos grupos e redes sociais que fazem deste espaço a porta de entrada de uma rede de solidariedade. E novamente, quando as fronteiras entre dia e noite se apagam ou seus limites se aproximam, a vida coletiva local se sente atraída pelo território da calçadas e das ruas.

Novamente, durante o fim-de-semana, resultado da divisão produtivista do tempo que separa os dias entre o trabalho e o repouso, a rua encontra outras formas de expressões de encontro coletivo diferente do tempo do trabalho, e que recriam a atmosfera da vida doméstica nas ruas do bairro. Nos fins-de-semana a vida do bairro começa no interior das casas, se estende as calçadas e converge para os entornos do Parque Farroupilha, um dos mais tradicionais territórios de vida comunitária de POA. ${ }^{13}$

\footnotetext{
12 Os habitantes da Vila, composta de "pessoas do povo", tem os mesmos problemas encontrados no bairro Bonfim, só que por diferentes motivos. Eles são obrigadas a conviver entre si à partir da manipulação dos estigmas sociais de vagabundos e marginais a eles atribuídos e que estão associados ao fracasso dos devaneios progressistas. Esta marca de deformação ampla atribuída a Vila é uma sobrecarga para os moradores dos loteamentos em relação aos moradores da favela e que necessitam de "purificação" na sua rotina diária de convivialidade. A pobreza dos habitantes da favela, sua miséria e abandono é, por um lado, a essência mesma de uma liberdade de aproveitar o prazer de estar-junto evitado pelos moradores do loteamento como forma de distinção interna no corpo coletivo da Vila. Em meio a fome, a sujeita e a imundície encontra-se, na favela, grupos de adultos e crianças à conversar, a rir e se deslocar, pés no chão, em meio aos caminhos tortuosos tanto quanto em torno do empilhamento de habitações miseráveis que se desenham no morro.

${ }^{13}$ Este fenômeno encontra-se presente também na parte do loteamento da Vila Ypu onde, o fim de semana, significa o momento das famílias e suas crianças se apropriam do espaço da rua, nos espaços em frente as suas edificações, colocando cadeiras nas calçadas, num reforço aos laços de solidariedade local. Para famílias de "mais posse", é o momento das crianças andarem de bicicletas nas ruas mais próximas . Senão é o momento de jogar bolitas, ou futebol no terreno baldio perto da escola, de brincar de "estatua", de contar histórias e piadas.
} 
A atmosfera urbana do fim-de-semana e dos dias da semana nas épocas de outono e inverno contrasta com os períodos da primavera e do verão, quando vemos nas calçadas e ruas repletas de pessoas de idade e suas cadeiras, carrinhos de bebês e mães, pequenas mesas lotadas de garrafas de cervejas vazias e pessoas de idade e sexo variada ao redor, numa poética social que pouco nos lembra a atmosfera pesada e densa das imagens infernais do bairro reproduzidas na mídia local. ${ }^{14}$

\section{Conclusão}

A construção de devaneios progressistas para o Bairro ( a construção de prédios de apartamentos com recuos, isolando seus moradores da ambiência da rua) tem alterado profundamente a paisagem local e suas formas de encontro coletivo, criando espaços vazios e uniformes constantemente subvertidos pela lógica simbólica de apropriação do espaço de sua população jovem.

Uma preocupação com a segurança e defesa do patrimônio individual tem feito com as famílias moradoras do local tendam a uma contração de seus laços coletivos com o bairro, alterando o patrimônio vivido de seus habitantes.

Torna-se importante pensar as consequiências das alterações que vem sofrendo o Bonfim nos seus territórios de socialidade coletivo, em termos de contração dos laços sociais, não só no que diz respeito ao processo de modernização do seu espaço de convivialidade urbana mas também no que tange a cultura do medo que leva ao enclausuramento de famílias em prédios de apartamentos cercados de grades. ${ }^{15}$

Disto pode derivar tanto o afastamento da comunidade local da formação cultural de sentido que ocupava o Bonfim, desde seus tempos mais remotos, na memória coletiva da cidade de

\footnotetext{
${ }^{14}$ Ao contrário do Bonfim ( mais próximo da ambiência da favela, na Vila Ypu, o fim de semana parece ser o tempo do encontro coletivo entre as crianças moradoras do loteamento, graças a presença do olhar atento dos pais, momento da presença de uma viscosidade de laços societais.

${ }^{15}$ Num estudo comparativo bairro Bonfim e Vila Ypu pode-se observar que a construção planificada de um espaço aberto, homogêneo e transparente, como a área do loteamento na Vila Ypu, não consegue dar conta da segurança de seus habitantes devido, justamente, a forma como apagam a diversidade que preside a vida coletiva de uma grande cidade. Quanto mais os devaneios progressistas sonham o paraíso na terra mais criam o inferno no corpo da cidade pois mesmo o espaço vazio esta carregado de uma "visão interior"., habitado pela fantasmagoria de seus habitantes.
} 
POA quanto a degradação dos valores afetivos de um território que vinculam seus habitantes entre si e destes com o bairro. ${ }^{16}$

Há que se pensar em formas de se revalorizar o gosto pela aglomeração e a atração pela vida coletiva que sempre orientou as formas de ocupação das ruas do bairro. Como outras formas de sociabilidades urbanas típicas das cidades brasileiras, o Bonfim ainda hoje nos lembra do prazer de se estar na multidão que obtemos quando vamos a praia, quando paramos num bar diante de um cerveja ou de um copo de cachaça (pouco importa) e, entre amigos e habitués locais, discute-se assuntos banais e corriqueiros de nosso dia-a-dia, ou, ainda, quando paramos nas esquinas de nossas moradias para conversar sobre os últimos capítulos da novela da Globo, os aspectos mais picantes da vida amorosa de algum político ou artista que esta em manchete, falar mal do nosso vizinho do lado, etc.

É necessário que se pense o preço que iremos pagar ao investirmos no isolamento seguro de nossa vida privada em prédios e moradias gradeadas, no consumo tranqüilo dos shoppings centers e na calmaria dos deslocamentos em nossos carros, isolando-nos de tais acontecimentos anódinos que fundam a vida comunitária de um bairro.

\footnotetext{
${ }^{16}$ Penso aqui que a monossemia totalitária e aniquilamento de uma viscosidade de laços societais devido ao urbanismo e a arquitetura modernista é capaz de reduzi a experiência estética de convívio coletivo numa tentativa de "domesticar" o espaço moralmente, numa desfiguração do espaço existencial.
} 